\title{
La golden share como instrumento de control estatal en empresas privatizadas
}

\author{
Helga Maria Saboia Bezerra ${ }^{1}$
}

\begin{abstract}
Resumen: Este artículo expone el mecanismo de la golden share, invento británico llevado a cabo con la función de servir de instrumento de control estatal en las empresas privatizadas a partir de la década de ochenta del siglo pasado, emulado por los demás países europeos con diversa denominación y similar finalidad. Presenta la jurisprudencia del Tribunal de Justicia de la Unión Europea en la materia, que le ha llevado a anular varios preceptos legales de Estados miembros que vulneraban, a través de tales restricciones, el principio de libre circulación de capitales y de libertad de establecimiento. Analiza, por fin, la adaptación del mecanismo a la legislación brasileña bajo el título de ação de classe especial, su previsión en los estatutos de concretas empresas privatizadas y el reciente protagonismo que tales instrumentos han tenido en los últimos años, ocasionando el temor a la reestatización por parte de los inversores.
\end{abstract}

Palabras-clave: Ações de classe especial. Acciones de oro. Competencia. Empresas privatizadas. Golden shares. Privatización. Unión Europea.

\begin{abstract}
This paper is concerned with the mechanism of golden share, a British invention carried out in order to serve as a state's control instrument in privatized enterprises since the 1980's, emulated by the other European countries with varied denomination and similar purpose. It presents European Court of Justice's case law on golden share that has prompted it to annul many Member State's rules that infringed, through such restrictions, the principles of free movement of capital and freedom of establishment. Finally, it examines the adjustment of the mechanism to the Brazilian legislation, under the title of ação de classe especial (action of special class), its disposal in the articles of association of specific privatized enterprises and the prominence that such instruments have had in the latest years, causing the fear of renationalization by investors.
\end{abstract}

Keywords: Ações de classe especial. Acciones de oro. Competition. Privatized enterprises. Golden shares. Privatization. European Union.

1 Doctoranda en Derecho, Universidad de Oviedo (España). Dirección electrónica: helgamsb@hotmail.com. 


\section{Introducción}

Ha sido una tendencia de los Estados europeos la previsión de instrumentos a través de los cuales mantener una cierta presencia o influencia en las empresas públicas que privatizan.

Juristas como Cano Soler (1998, p. 93) y Ortega Almón (2002, p. 72) coinciden en que existen diferentes técnicas jurídicas o societarias legales o estatutarias - para mantener el control estatal sobre las empresas privatizadas, como son: a) las acciones especiales o golden shares de origen británico; b) los núcleos duros (noyaux durs) de tradición francesa, por los que se mantienen unos poderes externos sobre ellas que garantizan su titularidad en manos amigas; c) la elaboración de legislación que impide las tomas de posición en los capitales de las empresas privatizadas sin previa autorización gubernamental; y d) el establecimiento de fórmulas contractuales que obliguen a los tenedores de las empresas privatizadas.

Otros, como García-Morato y Ariño Ortíz (2001, p. 335), añaden los blindajes empresariales - conocidos en Estados Unidos como poison pills como forma de defenderse frente a las OPAs indeseadas -, a través de los que o bien se limitan los derechos de voto cualquiera que sea la participación que se ostente en el capital; o bien se exigen determinadas condiciones para poder incorporarse al Consejo de Administración o para ser Presidente de la compañía, además de otras medidas que se puedan tomar.

En este artículo se va a hacer referencia, específicamente, a las acciones especiales o golden shares, en virtud del protagonismo que han tenido en el debate jurídico europeo de los últimos años.

Se analizarán las golden shares de algunos Estados miembros de la Unión Europea, especialmente España, cuya normativa, como la de otros Estados miembros - entre ellos Francia y Portugal -, tras haber sido criticada e investigada por las instituciones comunitarias, acabaron siendo desestimadas por el Tribunal de Justicia de la Unión Europea (TJUE, en adelante).

Se llevará a cabo, aún, el análisis de dichas prácticas de control previstas en la legislación brasileña, acogedora de las conocidas como ações de classe especial. 
Las golden shares han tenido ocasión de saltar a las páginas de los periódicos brasileños desde que, en 2007, el ministro de comunicaciones aireó la posibilidad de utilizar tal mecanismo en la compañía resultante de la fusión de dos empresas de telecomunicaciones (MARQUES, 2007).

En 2008, vuelven a tener protagonismo las acciones doradas al divulgarse las noticias de oposición del gobierno a la adquisición de la anglo-suiza Xstrata por la Vale - en la cual él posee ações de classe especial desde que fue privatizada -; y de la preparación de un Plano de Defesa Nacional, a partir del cual el gobierno pretende formar parte de las composiciones accionariales de las industrias privadas de armas por medio de golden shares (AMEAÇA, 2008).

\section{Antecedentes: las privatizaciones de las empresas públicas}

A mediados del siglo XX, tras la Segunda Guerra Mundial, la necesidad de reconstrucción de los Estados arrasados durante el conflicto bélico, hizo emerger las teorías según las cuales sólo la mano estatal y no más la mano invisible del mercado - podría permitir un desarrollo económico apropiado.

Terminada la guerra, que dividió Europa en dos bloques - el oriental, bajo el dominio de la URSS -, la devastación económica en que se encontraba el continente, con crecientes problemas sociales, sumado al temor que tenía EUA de que la mitad occidental cayera en manos comunistas, bajo control de la otra superpotencia, motivó que los norteamericanos, deseando garantizar la estabilidad en el viejo continente, propusieran a los Estados europeos un "Plan de Reconstrucción Europeo", conocido como Plan Marshall.

Aceptado por dieciséis países, puso a disposición de los gobiernos europeos una cantidad de dinero suficiente para la reconstrucción, que se caracterizaría por un mayor protagonismo del Estado en la vida económica y social, con la creación de la Organización Europea de Cooperación Económica - OECE (precursora de la actual OCDE), órgano gestor de la ayuda americana. 
En aquella segunda mitad del siglo XX la idea de servicio público - noción concebida por Hauriou, desarrollada por Duguit y ampliada por el Tribunal de Conflicts y el Conseil d'État franceses -, ganó el terreno fáctico, como instrumento de las Administraciones locales y estatales en su intento de superar el Estado liberal abstencionista.

El Estado, que pasó a instituirse en instrumento apto para proporcionar la igualdad material, atendiendo a las necesidades básicas de los ciudadanos, asumió la titularidad de los servicios sociales (educación, sanidad, benevolencia), que hasta entonces habían sido proporcionados por la Iglesia, y también de los económicos en red que, con el desarrollo tecnológico, se habían expandido con gran pujanza (electricidad, ferrocarril, teléfono, etc.).

La Gran Depresión de 1929 - que había llevado a la quiebra una importante cantidad de empresas privadas concesionarias de servicios públicos y propiciado el florecimiento de las teorías intervencionistas de John Maynard Keynes - desembocó en el desarrollo de la idea de Estado de Bienestar (Welfare State) que propugnó el surgimiento de una ola de nacionalizaciones que, a la reconocida titularidad estatal de servicios públicos, añadió la prestación de aquellos servicios, a través de la figura de la empresa pública.

Muchos de los servicios ofrecidos por el Estado, cuando éste comenzó a intervenir en la economía, pasaron a estar vinculados a aquellas empresas estatales que funcionaban en forma de monopolios públicos nacionales con vocación de operar en el arranque de la economía y en la reducción de las desigualdades sociales (ROLDÁN MARTÍN, 2000, p. 17-28).

Así, como señala Ruiz de Huidobro,

El sector público va adquiriendo peso, a través de la intervención del Estado en la economía, y su papel tardará en ser cuestionado. En todo caso no mientras la situación económica internacional fue floreciente. No será hasta que se perciban los efectos de las crisis del petróleo en los años 70. (RUIZ DE HUIDOBO, 1995, p. 450). 
A lo largo de cuatro décadas el Estado de Bienestar se sobredimensionó y se hizo omnipresente - siempre respaldado por la noción de servicio público y las empresas estatales - hasta llegar a provocar las dudas sobre su virtud y eficiencia.

Como hace notar Martín Retortillo, citado por Ruiz Huidobro (1995, p. 452), "la experiencia demuestra con carácter inexorable que el Estado, aun en la gestión directa de determinados servicios [...] propende, en principio, a ser siempre muy mal empresario”.

Así, desde un sector político y económico de cuño más liberal dígase neoliberal -, se empezó a proponer como alternativa un Estado mínimo, entonces posible en un contexto en que, dado el progreso científico y tecnológico alcanzado en los años ochenta, ya no se mantenía como natural el monopolio en ciertos tramos de actividades que un día estuvieron reservados (publicatio) al Estado.

Todo ello, sumado al clamor por más competencia en el contexto de una Unión Europea que se venía fortaleciendo en dirección a un mercado único, provocó el surgimiento de todo un conjunto de medidas de liberalización, desregulación y privatización.

Así, a partir de los años ochenta se empieza a recorrer el camino inverso al procedido con las nacionalizaciones de la posguerra, privatizando las empresas nacionales, con la intención de alcanzar objetivos como los de sanear las finanzas públicas, aumentar el sector productivo de la economía nacional, crear facilidades para el acceso del accionariado popular a los mercados financieros y limitar el poder del Estado en el sector económico y empresarial (RIDRUEJO; MERCHÁN; GONZÁLEZ, 2002, p. 6).

En los procesos de privatización fue pionera Inglaterra, y el modelo ha sido absorbido por la mayoría de los países, incluidos los latinoamericanos.

Como señala Cano Soler,

Si bien en el programa de 1979 del partido conservador inglés no aparece la palabra privatización, en poco menos de un año se 
convirtió en la receta de moda a aplicar, en mayor o menor medida, en más de un centenar de países durante la década de los años ochenta, y es hoy una de las políticas cuya discusión plantea más amplios horizontes. (CANO SOLER, 1998, p.77).

De hecho, aquella política fue inicialmente asociada con el gobierno de Margaret Thatcher en los años ochenta ${ }^{2}$ que, influida por el pensamiento económico de Friedrich A. von Hayek, privatizó muchas compañías de servicios públicos como British Telecom, British Gas, y compañías de agua y electricidad.

Tras el colapso del comunismo, los países del Este se esforzaron por adoptar la economía de mercado, y aún entre los regímenes manifiestamente socialistas como China, hay un movimiento hacia reformas basadas en el mercado libre y la privatización empieza a ser una realidad (UNITED STATES, 1996).

Aunque Estados miembros de la Unión Europea hayan procedido a la privatización de parte de sus empresas públicas, en el marco de la liberalización, esta ha sido una decisión libre, pues la Unión ha tomado una postura neutral en cuanto a la privatización (art. 345 TFUE, antiguo art. 295 TCE), no imponiéndola - los Tratados no prejuzgan en modo alguno el régimen de la propiedad en los Estados miembros -, sino más bien limitándose a exigir la apertura de mercado y la prohibición de ayudas estatales a las empresas.

Tal régimen hace que, mientras algunos países hayan procedido a una amplia privatización, otros han preferido no hacerlo, situación que puede llevar - y de hecho ha llevado - a la paradoja de que empresas privatizadas vuelvan a tornarse públicas bajo la propiedad de otro Estado Miembro que utiliza las libertades de establecimiento y de circulación de capitales para “salir de compras” por Europa.

2 Sin embargo, ya en los años 1970 un grupo de economistas chilenos aleccionados por sus profesores de la Escuela de Economía de la Universidad de Chicago, Milton Friedman y Arnold Harberger, aplicaron un programa de privatización en el país, apoyados por Pinochet. Por eso hay quien dice que fue Chile, y no Inglaterra, el país pionero en las reformas de los Estados a través de las privatizaciones (VERGARA ESTÉVEZ, 2005). 
Así, y como señalan Ariño Ortíz y Guirado (2006, p. 17), Estados como Francia, Portugal, Italia, Grecia, Irlanda y casi todos los incorporados a la Unión Europea recientemente han preferido acogerse al derecho de mantener el capital de las compañías - totalmente o en parte, a través de acciones de oro o golden shares - en sus manos en lugar de proceder a la privatización sin más.

En otros países, como Brasil, la privatización ha sido el principal medio por el cual el Estado se viene retirando de la economía y por lo tanto adquiere gran protagonismo el proceso.

En el país latinoamericano la privatización adquiere una importancia trascendental, lo que tampoco ha impedido, emulando en su legislación privatizadora el modelo europeo, la previsión del mecanismo de las golden shares (con la denominación de ações de classe especial), como han hecho muchos otros países del continente sudamericano.

\section{Concepto y origen de la golden share}

Como ocurre en cualquier instituto jurídico de expresión multinacional, innúmeras son las definiciones que se pueden encontrar en la doctrina - patria y extranjera - acerca de las golden shares.

De manera que, para elegir una de ellas a partir de la cual orientar el estudio, hay que servirse de algún criterio o método. En este caso, desde una intención crítica, el análisis se llevará a cabo tomando en consideración la lección de uno de los autores europeos que más censura ha arrojado al "artefacto” de las golden shares: el español Gaspar Ariño Ortiz, que en un artículo publicado en el año 2000 escribió:

En los últimos años hemos asistido al diseño, en el mundo económico y jurídico, de una serie de artefactos, cuyo objetivo final es entorpecer el mercado de empresas, introduciendo por vía legal o estatutaria una serie de elementos de blindaje que hagan muy difícil su adquisición por un tercero. Entre estos mecanismos, que se han extendido por Europa con el sorprendente silencio y complicidad de todos, las "acciones de oro" (golden shares), objeto reciente de polémica. (ARIÑO ORTÍZ, 2000). 
Sirviéndose, por lo tanto, de la definición de Ariño Ortiz y Guirado, se puede decir que

Por acciones de oro se entienden aquellos títulos dotados de prerrogativas especiales, que el Estado se reserva en empresas privatizadas pertenecientes a sectores estratégicos con el fin de controlar en último término la alta dirección de la compañía y su titularidad en manos cercanas. (ARIÑO ORTÍZ; GUIRADO, 2006, p.17).

La preocupación del jurista español se relaciona con el hecho de que surge en Europa un nuevo nacionalismo, que favorece los "campeones nacionales” y en atención al cual los gobiernos tienden a intervenir de mil maneras - una de las cuales a través de las acciones de oro - en las operaciones de reorganización empresarial, de manera que la sede de las grandes empresas se mantenga en territorio nacional. Con ello los gobiernos impiden la entrada en el país de inversores extranjeros, en un claro obstáculo a la consolidación del mercado único europeo (LÓPEZ DE CASTRO; ARIÑO ORTÍZ, 2001, p. 340-341).

En realidad, y como hacen notar varios autores, como Ivan Kuznetsov (2005, p. 23), las golden shares no necesariamente se refieren a la propiedad de reales acciones de la empresa privatizada. Instrumentos que confieran derechos especiales sobre la misma son suficientes para garantizar la influencia estatal de control aludida, a través de una ficción jurídica de participación accionarial simbólica del Estado en la empresa privatizada (FOURNIER; MIGUEZ, 2002, p. 47).

Del concepto se puede extraer por lo menos una característica que se constituye en fundamento de las golden shares, y de la que se puede con seguridad decir que es considerada en la casi totalidad de definiciones que se encuentra en la doctrina (por ejemplo: FOURNIER; MIGUEZ, 2002, p. 38; SÁNCHEZ, 2003, p. 32; KUZNETSOV, 2005, p. 22; TAPIA HERMIDA, 2008, p. 221). Y es el hecho de que las empresas privatizadas, que de ellas son objeto, pertenecen, en palabras de Uría Fernández (2000, p. 172), a “sectores estratégicos tradicionalmente considerados como monopolios naturales”, que suelen ser los de energía, 
electricidad, petróleo, telecomunicaciones, correos y transporte aéreo, para citar algunos.

La golden share fue primero utilizada por Inglaterra en 1982, con la privatización de Amersham Internacional (ÁLVAREZ; CALLEJA, 1995, p. 51) en el gobierno conservador de Margareth Thatcher y fue utilizada en todas las privatizaciones importantes llevadas a cabo en aquel país, incluidas las transacciones en las que las acciones fueron comercializadas a través de la Bolsa de Londres (ÁLVAREZ; CALLEJA, 1995, p. 47).

En 1986, en el mandato presidencial de François Miterrand y con Jacques Chirac como primer ministro, Francia copió el modelo inglés bajo el nombre de action spécifique en una ley ${ }^{3}$ que autorizaba el gobierno a tomar medidas de orden económica y social en las privatizaciones de 21 de sus empresas, entre las cuales Elf Aquitaine (JACQUIN, 1993; CHASPORT; RAMADIER, 1993) y empresas vinculadas al sector aeronáutico y de defensa como Thomson SA, Thomson CSF o Aérospaciale.

De hecho, y según Michel Laffitte, en referencia a las actions spécifiques francesas,

Si la protección de los intereses nacionales así lo exige, mediante decreto, se puede transformar una acción ordinaria de la empresa cuya privatización está planteada, en acción específica, a la cual se pueden vincular ciertos derechos: autorización por parte del ministro de Economía para rebasar los límites de participación en el capital de la empresa tras su privatización, nombramiento en el Consejo de Administración de la empresa de uno o dos representantes del Estado con voz consultiva y con poder de oposición a ciertas cesiones de activos previamente identificados, que podrían afectar a los intereses nacionales. Salvo los casos en que la independencia nacional se vea en juego, la acción específica puede, en todo momento, ser transformada definitivamente en acción ordinaria. De este modo, previamente a la privatización de Elf Aquitaine, se ha creado una acción específica. (LAFFITTE, 1994, p. 708).

3 Loi $n^{\circ}$ 86-912 du 6 août 1986 relative aux modalités d'application des privatisations décidées par la loi $n^{\circ}$ 86-793 du 2 juillet 1986 autorisant le Gouvernement à prendre diverses mesures d'ordre économique et social. 
A partir de aquellos años ochenta, en el largo y ancho del planeta, y a la medida que preparaban sus procesos de privatización, los países empezaron a prever, en sus legislaciones privatizadoras, mecanismos de control en las empresas privatizadas hechos a la medida de las golden shares inglesas.

\section{Aplicabilidad del instituto}

Esta intervención restrictiva puede darse a través de distintos medios: autorizaciones previas, derechos de veto, participación en la designación de miembros de los órganos de administración, control de sus decisiones, etc.

En este contexto es el Estado quien da la última palabra en operaciones estratégicas de las empresas privatizadas, si bien aunque las golden shares conceden a los gobiernos derechos especiales, ellos pueden no ejercerlos, si no lo juzgan necesario. Tales derechos pueden ser temporales, disponiendo de una fecha de vencimiento para su amortización, o ejercidos en una base permanente.

La abstención en el ejercicio de los poderes permitidos por el instituto, fue tema de que hizo gala el gobierno de España con ocasión de su derogación a partir de la imposición del TJUE, lo que no impidió, sin embargo, que funcionara el poder de disuasión de su mera existencia en más de una oportunidad (fusión Telefónica/holandesa KPN; compra de Hidrocantábrico por la alemana EnBW y la portuguesa EDP) (LA ACCIÓN DE ORO, 2006).

De semejante abstención presumen también los gobiernos brasileños, que hasta hoy no han utilizado - por lo menos no formalmente - sus ações de classe especial, de las que se hablará más adelante.

Esta característica disuasiva de la acción de oro ha sido considerada por algunos autores, como Álvarez y Calleja (1995, p. 45), de insignificante, una vez que su "presencia en la gestión de la sociedad y en la percepción que de ésta hace el mercado es mínima”. 
Sin embargo, se puede argumentar que si tal instrumento tiene poder disuasivo suficiente como para "inducir, mover a alguien con razones a mudar de dictamen o a desistir de un propósito" (REAL ACADEMIA ESPAÑOLA, 2001), que tal es, según el Diccionario de la Real Academia Española, el significado del vocablo “disuadir”, entonces aquél instrumento, de “mínimo” no tiene nada. Está, al contrario, dotado de fuerza suficiente para, por su sola existencia, desalentar decisiones que serían contrarias al deseo del tenedor de la acción especial, es decir, del gobierno.

Otra cosa es que la presencia de unos derechos especiales en la gestión de la empresa no sea percibida por el mercado. De hecho, las golden shares siguen siendo las grandes desconocidas de los, hoy tan comunes, procesos de privatización, no sólo entre el accionariado popular como entre los consumidores de las empresas que fueron traspasadas a manos privadas.

Sin embargo, como aquellos mismos autores reconocen,

La mera existencia de la acción especial, aun en el caso de que las facultades que ésta incorpora no sean realmente ejercitadas por el gobierno, puede acarrear una percepción negativa de la empresa por parte del mercado. La acción especial es, en cierta medida, contraria al verdadero espíritu de la privatización y de la libre competencia. (ÁLVAREZ; CALLEJA, 1995, p. 47).

\section{La utilización de la golden share por los estados miembros de la unión europea: una práctica habitual}

Si bien la jurisprudencia del TJUE lo considere en no pocos casos incompatible con el Derecho comunitario, el mecanismo de las golden shares ha estado presente en más de un centenar de empresas de la Unión Europea. $^{4}$

4 En una recapitulación de las restricciones (acciones de oro, derechos especiales) aplicadas por los Estados miembros de la Unión Europea en las inversiones directas intracomunitarias, Hernández López se refiere a las siguientes: Francia - instituyó las acciones de oro (action 
Energía (Asunto C-483/99, Comisión c. Francia), electricidad (Asunto C-174/04, Comisión c. Italia), gas (Asunto C-503/99, Comisión c. Bélgica), telecomunicaciones y correos (Asunto C-283/04, Comisión c. Países Bajos), son los sectores en los que se han manifestado las empresas con acciones de oro. Los Estados han justificado su uso con el argumento de que el sector público debe seguir velando por recursos escasos de interés nacional que pasan a ser gestionados por empresas privadas.

Como hace notar Hernández López, uno de los argumentos de que se utilizan los gobiernos de los Estados miembros para mantener los derechos especiales (GS o golden shares) sobre las empresas que privatizaron, es el principio de neutralidad del art. 295 TCE (actualmente art. 345 TFUE, según el cual "los Tratados no prejuzgan en modo alguno el régimen de la propiedad en los Estados miembros”):

Según éste, el Estado tiene la exclusiva capacidad jurídica de privatizar y/o nacionalizar cualquier tipo de bienes o servicios, sin que la legislación comunitaria pueda interferir en su decisión. Se trata, pues, de un dominio exclusivamente nacional. El Estado puede ejercer esta capacidad de decisión sobre una empresa entera

spécifique) en la legislación creada con ocasión de la privatización de 21 empresas públicas. De hecho sólo las utilizó en el caso de la privatización de Elf Aquitaine; Bélgica - creó también una acción de oro en la privatización de la Société Nationale d’ Investissement; al mismo tiempo el Gobierno belga se reservó “derechos especiales” (SR) en las compañías Distrigaz, Synatom y en la Société Nationale de Transport par Canalisations; Reino Unido usó las golden share en la privatización de 20 empresas públicas, entre ellas British Energy, British Airport Authorities, Roll-Royce, British Gas, National Power, etcétera; Irlanda - se reservó special rights en las tres compañías públicas privatizadas más importantes: Irish Life, Greencore Group y Telecom. Eiream; Holanda - impuso derechos especiales (SR) en KPN y TNP; Dinamarca - hizo lo mismo con Teledanmark y Copenhagen Airport; Suecia - también lo hizo en la privatización de Celsius Industrier; Finlandia - se reservó derechos especiales (SR) en la Gasum OY, industria del gas; Alemania - impuso restricciones en la privatización de Lufthansa así como en Volkswagen; Luxemburgo - hizo lo mismo con SES, un operador global de satélites; Portugal - impuso restricciones a la inversión directa comunitaria en banca, seguros, energía y transportes. Tal fue el caso de Cementos de Portugal, Telecom, Eletricidade, Petróleos de Portugal, etc.; Italia - decretó SR en favor del Gobierno en las privatizaciones de ENI, Stet y Telecom, Enel; Finalmente, en España, el Gobierno se reservó SR en Repsol, Telefónica, Argentaria, Tabacalera y Endesa (HERNÁNDEZ LÓPEZ, 2006, p.158). 
o sobre una parte de ella ya que el que puede lo más puede lo menos. De la misma manera, un gobierno puede privatizar todos los derechos de una empresa o sólo unos pocos, dejando algunos en manos de los poderes públicos. Éste es el caso de las GS, que en el fondo equivalen a una privatización parcial, puesto que los Estados se quedan con unos cuantos de los derechos que antes ostentaban. (HERNÁNDEZ LÓPEZ, 2006, p.160).

\section{Posición del tjue sobre las golden shares}

El TJUE no acepta el argumento simplemente y sigue el criterio de la Comisión Europea, uno de cuyos principios se refiere al artículo 295 TCE antes mencionado (actualmente art. 345 TFUE), señalando que si los Estados miembros guardan el derecho exclusivo y soberano de decidir la propiedad “privada/pública” de las empresas,

Esto implica que la decisión de privatizar o nacionalizar es exclusiva de los Estados Miembros, los cuales pueden ejercerla o no, sin que medie obligación alguna. No obstante, si la ejercen, han de hacerlo ajustándose fielmente al Tratado, que ellos mismos crearon y refrendaron (HERNÁNDEZ LÓPEZ, 2006, p. 162).

Y el Tratado, más bien Tratados, en plural - ya que se espera que en enero de 2009 entren en vigor, modificados por el Tratado de Lisboa, el Tratado de la Unión Europea (TUE) y el Tratado constitutivo de la Comunidad Europea (TCE), ganando, este último, la denominación de Tratado de Funcionamiento de la Unión Europea (TFUE) - lo que propugnan es la libertad de circulación de personas, servicios, bienes y capital, que posibilite la existencia de un mercado económico único. De manera que la decisión sobre privatizar o no sus empresas públicas, de modo algún da derecho a un Estado miembro de hurtarse de la obligación, asumida en los Tratados, de respetar la libertad de establecimiento y de circulación de capitales frecuentemente heridas por las golden shares, como se verá en adelante. 
El TJUE ha analizado normas internas de diversos países, entre ellos Portugal, Francia y Bélgica, cuyas tres sentencias, todas de 4 de junio de 2002 (C-367/98; C-483/99 y C-503/99 respectivamente), han tenido gran repercusión y han significado "un recorte drástico de las facultades que puede reservarse el Estado en sociedades privatizadas” (FOURNIER; MIGUEZ, 2002, p. 57), línea jurisprudencial que se viene consolidando a partir de entonces.

En el caso de Francia y en el de Bélgica la Comisión Europea, quien abrió los procedimientos ante el Tribunal, ${ }^{5}$ apuntaba a empresas concretas privatizadas (Elf Aquitaine francesa y SNTC y Distrigaz belgas), mientras en el caso de Portugal el expediente abierto por la Comisión embestía directamente contra la legislación contemplativa del régimen restrictivo de los direitos especiais, dispuestos en la Ley-marco de privatizaciones (Ley 11/90, de 5 de abril de 1990).

Habiendo considerado ilegales los límites impuestos por los gobiernos de Francia y Portugal a la participación accionarial extranjera en algunas de sus ex estatales, el TJUE mantuvo, con restricciones, los derechos del gobierno belga sobre una empresa privatizada del sector de gas (Distrigaz).

Los jueces decidieron que algunas restricciones en el mercado interior europeo son aceptables, siempre que estén basadas en los requerimientos incuestionables del interés general y sean proporcionales a los fines de interés público perseguidos. Los gobiernos, según el TJUE, podrán mantener controles sobre empresas privatizadas en casos excepcionales, en sectores estratégicos como de defensa, pero esa práctica tendrá que ser muy limitada (MUÑOZ MACHADO, 2004, p. 1068-1074).

Lo que pone de manifiesto el TJUE en las sentencias de 4 de junio de 2002 es que no está completamente prohibido el mantenimiento de poderes especiales de intervención del Estado en empresas privatizadas,

5 La Comisión Europea, "guardiana de los Tratados”, es competente para controlar la aplicación del Derecho Comunitario en y por los Estados miembros. Si un Estado miembro ha incumplido sus obligaciones, la Comisión puede emitir un dictamen motivado tras haberle dado la oportunidad de presentar sus observaciones. Si este dictamen no produce efectos, la Comisión puede recurrir al Tribunal de Justicia de la Unión Europea - TJUE. 
si se atiene a unos límites respetuosos con las libertades previstas en los Tratados y trazados por dichas sentencias.

Como apunta Ivan Kuznetsov, “para preservar derechos especiales en compañías privatizadas, los Estados miembros deberían considerar que sus golden shares deben satisfacer los criterios de legalidad establecidos por el Tribunal”, una vez que

La Comisión Europea dejó claro que no toleraría restricciones injustificadas de los Estados miembros a la libre circulación de capitales y a la libertad de establecimiento en temas concernientes a inversiones internacionales. (KUZNETSOV, 2005, p. 22, 24, traducción nuestra). ${ }^{6}$

Es importante notar, sin embargo, el punto para el que llama la atención Hernández López, según quien,

El Tribunal nunca ha sentenciado que las acciones de oro en general sean incompatibles con los Tratados de la Unión Europea. Sólo las ha condenado en los casos concretos que ha tenido que enjuiciar. Señalar esto es importante porque, a pesar de la claridad de las sentencias, pueden seguir existiendo en el futuro toda una serie de denuncias sobre otros casos concretos. A mi entender, no obstante, y gracias a los argumentos que desarrolla el Tribunal en sus sentencias ya dictadas, el debate conceptual está cerrado. (HERNÁNDEZ LÓPEZ, 2006, p. 163).

Finalmente, aún para Hernández López, el TJUE admite, aunque no de manera explícita, que la salvaguardia del interés público (por ejemplo, garantizar el suministro de energía al país, el buen funcionamiento de las telecomunicaciones, etc.) pueda llevar a los gobiernos a poner ciertas trabas a la libertad de movimientos de capital.

6 "To preserve special rights in privatised companies, Member States should consider that their golden shares must satisfy the criteria of legality established by the Court."; "European Commission made it clear that it would not tolerate Member States'unjustified restrictions on free movement of capital and freedom of establishment in issues concerning cross-border investments." 
Dado que esto deja abierta la cuestión sobre cuándo exista esa necesidad imperativa de proteger el interés general o público, el Tribunal se apresura a fijar más concretamente las condiciones que deben acompañar el recurso a dicho argumento para poder aplicar legalmente restricciones a las inversiones directas transfronterizas. Esas condiciones son las siguientes: que no sean discriminatorias (por ende, "los núcleos duros" no están permitidos); que estén justificadas por las exigencias imperativas del interés general; que se basen en un conjunto de criterios objetivos, estables en el tiempo y dados a conocer públicamente; que respeten el principio de proporcionalidad; que se adecuen al objetivo que persiguen. Estas precisiones del Tribunal son muy útiles en la práctica, ya que nociones tales como "orden público" o "interés general” son demasiado amplias y se prestan fácilmente a abusos de interpretación. (HERNÁNDEZ LÓPEZ, 2006, p. 164). ${ }^{7}$

Una medida restrictiva del ejercicio de las libertades garantizadas por los Tratados sólo es compatible con el Derecho comunitario si está amparada por alguna de las excepciones previstas en los mismos Tratados o si atiende a un objetivo legítimo de interés público reconocido por la jurisprudencia como "razones imperiosas". En sendos casos la medida tiene que ser adecuada para alcanzar el objetivo que se persigue y no puede ir más allá de lo estrictamente necesario para ello (principio de proporcionalidad).

Más recientemente, en sentencia de 6 de diciembre de 2007 (en los asuntos acumulados C-463/04 y C-464/04), el TJUE declaró la ilegalidad de la azioni d'oro que el Ayuntamiento de Milán (Italia) mantenía en la privatizada sociedad de gas y electricidad Azienda Elettrica Milanese (AEM) (SANTONASTASO, 2007) al considerar que vulnera la libertad de movimiento de capitales e inhibe la participación de otros inversores.

\footnotetext{
7 En cuanto a las medidas discriminatorias, tratan de las restricciones que se aplican por un Estado Miembro de la Unión Europea a los nacionales de otro Estado Miembro. Las no discriminatorias son las que se aplican no sólo a los ciudadanos de otro Estado Miembro, como a sus propios nacionales. Las primeras son incompatibles con los Tratados de la Unión, a menos que se puedan acoger a alguna de sus excepciones. Las segundas sólo serán admitidas en la medida en que se basen en criterios objetivos, estables y públicos y se puedan justificar por razones imperiosas de interés general. En cualquier caso ha de ser respetado el principio de proporcionalidad (HINOJOSA MARTÍNEZ, 2003, p.14).
} 


\section{El caso español}

En España la regulación de las llamadas acciones de oro fue recogida en la Ley 5/1995, de 23 de marzo, de Régimen Jurídico de Enajenación de Participaciones en Determinadas Empresas (desarrollada por el Real Decreto 1515/1995, de 15 de septiembre), también conocida como Ley de Privatizaciones.

La principal finalidad de la Ley 5/1995 estribaba en responder a la garantía del interés público presente en la actividad de determinadas empresas que habían estado bajo el control de la Administración Pública titular de la totalidad o de la mayoría del capital social y que entraron en proceso de privatización, como ENDESA (electricidad), REPSOL (petróleo y energía), TELEFÓNICA (telecomunicaciones), IBERIA (transporte aéreo), ARGENTARIA (banca) e incluso TABACALERA (tabaco).

Hasta entonces, como la propia Ley expresaba en su exposición de motivos, esta garantía había estado cubierta con la propiedad pública de las empresas en cuestión. Sin embargo, el nuevo escenario en que, a partir de entonces, iban a encontrarse aquellas empresas cuya propiedad iba a pasar a manos privadas y cuyo centro de control iba, por ende, a situarse extramuros de los poderes públicos, exigía la adopción de medidas específicas en garantía del interés público inherente a su actividad.

La Ley de Privatizaciones instauró, así, un régimen de autorización administrativa previa a la realización de determinados actos, entre los que se incluía la enajenación a terceros de porciones significativas del capital social.

El legislador, “como sustitutivo de la propiedad de capital social”, estableció la alternativa de sujeción a la autorización administrativa previa algunos acuerdos y actos relacionados con las empresas mercantiles en las que el Estado tuviera una participación accionarial, directa o indirecta, superior al 25\% y estuvieran controladas por el socio estatal, y cuando ocurriera algún de los siguientes requisitos: a) prestar servicios esenciales o servicios públicos formalmente declarados como tales; b) desarrollar actividades sujetas por ley y razones de interés público a un específico régimen administrativo de control, especialmente de los sujetos que las 
realicen (“actividades reguladas”); c) estar exenta total o parcialmente de la libre competencia en los términos del artículo 86 del Tratado CE (art. 106 TFUE).

Sin embargo, este régimen fue cuestionado desde el punto de vista de su adecuación al derecho comunitario europeo, lo que dio lugar a un proceso ante el TJUE, que atacó directamente la legislación española. Concluyó con la Sentencia de 13 de mayo de 2003 (asunto C-463/00), en la que fueron declarados contrarios a aquel derecho los preceptos de la Ley 5/1995, de 23 de marzo, que constituían el núcleo de dicho régimen.

El TJUE, declarando que los artículos 2 y 3, apartados 1 y 2, de la Ley 5/1995, de 23 de marzo, en la medida en que establecían la aplicación de un régimen de autorización administrativa previa, eran incompatibles con los arts. 43 y 56 TCE (actualmente arts. 49 y 63 TFUE), afirmaba que este instrumento era contrario a la libertad de establecimiento ${ }^{8}$ y a la libertad de circulación de capitales ${ }^{9}$ en el seno de la Unión Europea.

Así, el 27 de mayo de 2006 (fecha de su publicación en el Boletín Oficial del Estado) entró en vigor la Ley 13/2006, de 26 de mayo, que derogó el régimen de enajenación de participaciones públicas en determinadas empresas establecido por la Ley 5/1995, de 23 de marzo, y sus disposiciones de desarrollo y ejecución, con la finalidad de cumplir aquella sentencia del TJUE, que declaró ilegal la norma española.

8 Art 49 TFUE (antiguo art. 43 TCE): “En el marco de las disposiciones siguientes, quedarán prohibidas las restricciones a la libertad de establecimiento de los nacionales de un Estado miembro en el territorio de otro Estado miembro. Dicha prohibición se extenderá igualmente a las restricciones relativas a la apertura de agencias, sucursales o filiales por los nacionales de un Estado miembro establecidos en el territorio de otro Estado miembro. La libertad de establecimiento comprenderá el acceso a las actividades no asalariadas y su ejercicio, así como la constitución y gestión de empresas y, especialmente, de sociedades, tal como se definen en el párrafo segundo del artículo 54, en las condiciones fijadas por la legislación del país de establecimiento para sus propios nacionales, sin perjuicio de las disposiciones del capítulo relativo a los capitales.”

9 Art 63 TFUE (antiguo art. 56 TCE): “1. En el marco de las disposiciones del presente capítulo, quedan prohibidas todas las restricciones a los movimientos de capitales entre Estados miembros y entre Estados miembros y terceros países. 2. En el marco de las disposiciones del presente capítulo, quedan prohibidas cualesquiera restricciones sobre los pagos entre Estados miembros y entre Estados miembros y terceros países.” 


\section{Las golden shares en Brasil: las ações de classe especial}

Aunque haya sido el principal agente de la actividad económica empresarial a partir de mediados y hasta casi el final del siglo pasado, el Estado brasileño no ha ejercido siempre con preponderancia ese papel.

Las compañías responsables de los servicios de red (eléctricas, sanitarias, telecomunicaciones, transportes, ferrocarriles), - que, por estratégicas, son las que, junto a las de defensa, principalmente interesan a este estudio, ya que en ellas, en general, recaen las acciones de oro nacieron de la mano del emprendedor privado - nacional y no pocas veces extranjero - a finales del siglo XIX.

La ausencia del poder público en la construcción de la infraestructura industrial brasileña del final del siglo XIX, fue comentada por Paulo Prado ya en 1928, en su Retrato do Brasil, al decir que

Foi o particular que desbravou a mata, que ergueu as plantações, que estendeu pela terra virgem os trilhos dos caminhos de ferro, que encheu de gado as grandes pastagens, que fundou cidades, abriu fábricas, organizou companhias e importou o conforto da vida material. O poder público, pacientemente, esperou os frutos da riqueza semeada. E logo em seguida criou o imposto" (PRADO, 2001, p. 201).

Desde la segunda mitad del siglo XX, las empresas de servicios públicos son consideradas como monopolios naturales, controladas por el Estado - que a partir del gobierno Vargas procedió a una intensa nacionalización de empresas -, debiéndose tal situación - su constitución en monopolios naturales - a las economías de escala propias de aquellas actividades.

Sin embargo, en el último decenio del siglo $\mathrm{XX}$ se introduce la competencia en la mayoría de las actividades en las que el Estado brasileño estuvo directa o indirectamente involucrado, y así determinadas actividades de los sectores de red que, por su naturaleza, admiten la competencia, pasaron a ser también liberalizadas, permitiéndose su prestación por la iniciativa privada, a quien empezó a ser devuelta - a 
partir de los años noventa -, con las privatizaciones, la propiedad de las empresas antes estatales (CASTELAR PINHEIRO; FUKASAKU, 2000).

Al enviar al Congresso Nacional en marzo de 1990 la Medida Provisoria $\mathrm{n}^{0} 115$, que se tornó la Ley 8.031/1990, de 12 de abril, que instituía el Programa Nacional de Desestatização (PND en adelante), el Ejecutivo brasileño intentaba, con la privatización, alcanzar los siguientes objetivos:

a) Reordenar la posición estratégica del Estado en la economía, transfiriendo a la iniciativa privada actividades indebidamente exploradas por el sector público (art. $\left.1^{\circ}, \mathrm{I}\right)$;

b) Reducir la deuda pública (art. $\left.1^{\circ}, \mathrm{II}\right)$;

c) Permitir la retomada de inversiones en las empresas y actividades que vinieran a ser transferidas a la iniciativa privada (art. $1^{\circ}$, III);

d) Contribuir a la modernización del parque industrial brasileño, ampliando su competitividad y reforzando la capacidad empresarial en los diversos sectores de la economía (art.1 ${ }^{\circ}, \mathrm{IV}$ );

e) Permitir que la administración pública concentrase sus esfuerzos en las actividades en que la presencia del Estado fuera fundamental para la consecución de las prioridades nacionales $\left(\operatorname{art} .1^{\circ}, \mathrm{V}\right)$;

f) Contribuir al fortalecimiento del mercado de capitales a través del aumento de la oferta de valores mobiliarios y de la democratización de la propiedad del capital de las empresas que integraran el Programa. (art. $\left.1^{\circ}, \mathrm{VI}\right)$.

Podrían ser privatizadas las empresas controladas, directa o indirectamente, por la União e instituidas por ley o acto del Poder Ejecutivo (art. $\left.2^{\circ}, \mathrm{I}\right)$; o creadas por el sector privado y que, por cualquier motivo, pasaran al control, directo o indirecto, de la União (art. $2^{\circ}$, II).

Las privatizaciones se darían de una de las siguientes formas ( $\left.\operatorname{art} .4^{\circ}\right)$ :

a) Alienación de participación societaria, incluso de control accionario, de preferencia a través de la pulverización de acciones junto al público, empleados, accionistas, suministradores $\mathrm{y}$ consumidores; 
b) Apertura de capital;

c) Aumento de capital con renuncia o cesión, total o parcial, de derechos de subscrición;

d) Transformación, incorporación, fusión o cisión;

e) Enajenación, arrendamiento, locación, comodato o cesión de bienes e instalaciones;

f) Disolución de empresas o desactivación parcial de sus emprendimientos, con la consecuente enajenación de sus activos.

Y, aún, la privatización de empresas prestadoras de servicios públicos, mediante una de las modalidades previstas en el art. $4^{\circ}$, con la delegación, por el Poder Público, de la concessão o permissão del servicio objeto de la exploración, ya que, aunque privatizadas las empresas estatales, la titularidad del servicio de interés público seguía - y sigue siendo de la União, de los Estados y de los Municipios.

La privatización fue considerada, por aquella Ley, como la enajenación, por la União, de derechos que le asegurasen, directamente o a través de otras controladas, preponderancia en las deliberaciones sociales y el poder de elegir la mayoría de los administradores de la sociedad $\left(\operatorname{art.} 2^{\circ}, \S 1^{\circ}\right)$.

La Ley preveía la creación de ações de classe especial a partir de sugerencia, al Presidente de la República, por parte de la comisión directora del programa (art. $6^{\circ}$, XIII) y que solamente podrían ser subscritas por la União (art. $6^{\circ}, \S 2^{\circ}$ ).

Según el art. $8^{\circ}$, siempre que hubiera razones que lo justificaran, la União detendría, directa o indirectamente, ações de classe especial del capital social de empresas privatizadas, que le confirieran poder de veto en determinadas materias, las cuales deberían ser caracterizadas en los estatutos sociales de las empresas.

Las ações de classe especial (golden shares) otorgarían a la União capacidad de intervención en la administración de las empresas privatizadas - muchas de las cuales pasarían a manos de inversores extranjeros -, a través del poder de voto y de veto, siempre que estuviera en riesgo el interés público. Estas acciones, diferenciadas de todas las 
otras representativas del capital social, tendrían poder de veto en materias como, por ejemplo, cambio del objeto social, cambio de sede de la empresa, cese de proyectos o inversiones, alteración de la composición del Consejo de Administración o del régimen de dirección.

En 1997, la Ley 9.491, de 9 de setiembre, que derogó la Ley 8.031/1990, de 12 de abril, amplió considerablemente el alcance de las ações de classe especial, al no limitarlas más al poder de veto, pudiendo darles otros diversos poderes (poderes especiais em determinadas matérias), desde que previstos explícitamente en los estatutos sociales de las empresas.

Mientras el art. $8^{\circ}$ de la Ley 8.031/1990 rezaba:

Sempre que houver razões que o justifiquem, a União deterá, direta ou indiretamente, ações de classe especial do capital social de empresas privatizadas, que lhe confiram poder de veto em determinadas matérias, as quais deverão ser caracterizadas nos estatutos sociais das empresas, de acordo com o estabelecido no art. $6^{\circ}$, inciso XIII e $\S \S 1^{\circ}$ e $2^{\circ}$ desta lei.

El art. $8^{\circ}$ de la Ley 9.491/1997 disponía:

Sempre que houver razões que justifiquem, a União deterá, direta ou indiretamente, ação de classe especial do capital social da empresa ou instituição financeira objeto da desestatização, que lhe confira poderes especiais em determinadas matérias, as quais deverão ser caracterizadas nos seus estatutos sociais.

Surgió también, dentro de los programas de desestatización estaduais, legislación previsora de ações de classe especial, como fue el caso de Sergipe (art. $6^{\circ}$ de la Ley 3.781, de 23 de mayo de 1996), São Paulo (art. $9^{\circ}$ de la Ley 9.361, de 5 de julio de 1996) y Roraima (art. $9^{\circ}$ de la Ley 225, de 30 de junio de 1999), para citar sólo tres ejemplos.

En 2001 la Ley 10.303, de 31 de octubre añadió un $\S 7^{\circ}$ al art. 17 de la Ley 6.404, de 15 de diciembre de 1976 (Lei de Sociedades por Ações), cuyo tenor era el siguiente: 
Nas companhias objeto de desestatização poderá ser criada ação preferencial de classe especial, de propriedade exclusiva do ente desestatizante, à qual o estatuto social poderá conferir os poderes que especificar, inclusive o poder de veto às deliberações da assembléia-geral nas matérias que especificar.

Así, se ve que União, Estados y Municipios pudieron crear sus propias golden shares al privatizar sus compañías, acciones estas de exclusiva propiedad del ente desestatizante, estando vedada su transferencia a terceros, aunque éstos fueran personas jurídicas de derecho público.

Sin embargo, en el inicio de las privatizaciones, todavía no tenía el Estado una voluntad realmente firme y clara de retirarse del escenario económico. Admitía la privatización en un momento en que era este el camino que tomaban los demás países y que estaban imponiendo los organismos financieros internacionales (Consenso de Washington).

Necesitaba dinero, nuevas inversiones, ya no podía seguir como el aparato pesado que era. No obstante, esta comprensión de la necesidad de privatizar se quedaba a medio camino. Se dibujaba una privatización que garantizase al Estado seguir como autoridad en las empresas, con su protagonismo intocable (ações de classe especial).

\section{Estatales brasileñas privatizadas con previsión de la restricción}

En el inicio del proceso de privatización, pese a la timidez de la voluntad privatizadora, se concentraron esfuerzos para la venta de empresas estatales pertenecientes a sectores estratégicos: empresas siderúrgicas, petroquímicas y de fertilizantes - sin duda una privatización más fácil de llevar a cabo que la del área de servicios, que necesita una legislación reguladora -. El Estado entendía que, en lugar de ejecutar actividades que el sector privado era plenamente capaz de realizar, debería ocuparse de áreas como educación, salud, seguridad y regulación (CASTELAR PINHEIRO; FUKASAKU, 2000). 
Una de las primeras empresas brasileñas privatizadas, la minera Companhia Vale do Rio Doce, lo fue con la previsión de unas ações preferenciais de classe especial. Así, el gobierno federal dispone de un mecanismo muy eficiente para interferir en los rumbos de la compañía, ya que tiene en su poder una golden share de la que echar mano en caso de no concordar con algunas de sus decisiones.

El estatuto de la empresa dispone que

[...] As ações preferenciais de classe especial, golden shares, devem ser obrigatoriamente de titularidade da União Federal. O detentor das ações preferenciais de classe especial tem os mesmos direitos (incluindo aqueles relativos a voto e preferências de dividendo) dos detentores de ações preferenciais Classe A. Adicionalmente, o detentor das ações preferenciais de classe especial tem o direito de vetar quaisquer propostas em relação aos seguintes assuntos: 1. alteração de nossa denominação social; 2. mudança de nossa sede social; 3. mudança do nosso objeto social relativamente à exploração de jazidas minerais; 4. liquidação de nossa empresa; 5. qualquer alienação ou encerramento das atividades de uma ou mais das seguintes etapas dos sistemas integrados de nossa exploração de minério de ferro: Jazidas minerais, depósitos de minério, minas, ferrovias, portos e terminais marítimos; 6. qualquer modificação dos direitos atribuídos às espécies e classes das ações de nossa emissão; 7. qualquer modificação de quaisquer dos direitos atribuídos por nosso Estatuto Social à ação preferencial de classe especial. ${ }^{10}$

Aunque haya cambiado de nombre - de "Companhia Vale do Rio Doce” para "Vale” - con la intención de romper los lazos que aún unían su imagen a la de una ex-estatal, librándola del antiguo logotipo fácilmente asociado a las patentes militares de la época de la dictadura - sin utilizarse la União de la prerrogativa de vetar la alteración de la denominación social -, es notable la rigidez en que se ha quedado la empresa con la previsión de esta golden share en su estatuto. Quizá los artífices de esta ação de classe especial hayan temido que la minera se transformara en una cadena de cafeterías o en algún negocio menos virtuoso.

10 Texto disponible en la página web de la Compañía: <http://www.vale.com>. 
El gobierno brasileño tiene poder también sobre la Empresa Brasileira de Aeronáutica - Embraer. En el proceso de privatización de la compañía la União mantuvo una golden share, lo que le otorga poder de veto en las votaciones de cuestiones de interés estratégico. El estatuto social de Embraer prevé la existencia de una ação ordinária de classe especial, detenida por la União, que preservará todas sus prerrogativas en cuanto sea detenida por ella (conforme art. $8^{\circ}$ de la Ley n ${ }^{0}$ 9.491/97). La ação ordinária de classe especial confiere a la União poder de veto en las siguientes materias:

a) Cambio de denominación de la compañía o de su objeto social;

b) Alteración y/o aplicación de la logomarca de la compañía;

c) Creación y/o alteración de programas militares, que involucren o no la República Federativa do Brasil;

d) Capacitación de terceros en tecnología para programas militares;

e) Interrupción del suministro de piezas de mantenimiento y reposición de aeronaves militares;

f) Transferencia del control accionario de la compañía;

g) Otras alteraciones en legislación especifica.

El sometimiento de la privatizada Embraer a la voluntad del gobierno le ha llevado a protagonizar en septiembre de 2008 un humillante ejemplo de sujeción a la más abierta intervención estatal cuando, con ocasión de la visita de Estado de la Presidente Cristina Kirchner, el gobierno involucró la empresa aeronáutica en parte de los proyectos bilaterales del área de Defensa, afirmando que tendrá que desarrollarlos con la argentina Área Material Córdoba-AMC. Cuestionado sobre la resistencia de la compañía brasileña, privada, en aceptar este acuerdo entre gobiernos, un asesor de la Presidencia afirmó sencillamente que "el gobierno tiene poder sobre Embraer” (CHRISPIN MARIN, 2008).

Es claro que en algunos puntuales casos, relacionados a intereses realmente estratégicos, se justifica el mantenimiento de este tipo de restricción en empresas privatizadas, pero desde luego no es el caso de una compañía minera como la Vale - aunque ciertos sectores como 
los militares consideren la minería de hierro como la médula de toda estrategia de seguridad nacional -, donde el gobierno sólo ha aumentado su participación, en la que la União, como se ha visto, dispone de golden share.

\section{Golden shares: mecanismo de prevención en contra del "peligroso" inversor privado y extranjero}

Es conveniente dedicar atención a un tema que, si descansa bajo el manto del silencio, tarde o temprano llegará a despertar las atenciones de los espíritus más liberales cuando, en una vuelta al más rancio socialismo, un gobierno se establezca en Brasil con la intención de re-estatizar empresas privatizadas a lo largo de los tres últimos lustros.

Como señala Manuel Gonçalves Ferreira Filho (2005, p. 365), en el orden constitucional brasileño "não há garantia segura e efetiva contra o avanço da estatização na economia”.

Así, empresas que en la década de los noventa del pasado siglo fueron devueltas, a través de las privatizaciones, al mercado, pueden, perfectamente, volver a ser nacionalizadas. No es difícil que ello ocurra, una vez que en América Latina se han visto gobiernos populistas como los de Hugo Chávez en Venezuela, de Evo Morales en Bolivia, y de Cristina Kirchner en Argentina nacionalizando empresas que no hace mucho fueron privatizadas en sus países. Véase los tan sonados casos de Aerolíneas Argentinas y Austral (Argentina, 2008), del Banco Santander y de la cementera mexicana Cemex (Venezuela, 2008), de Repsol-YPF (Bolivia, 2007).

Ni que decir tiene que muchas críticas a su sesgo estatalizante ha cosechado ya el actual gobierno brasileño, tanto dentro como fuera del país, en el caso reciente de la pretendida creación de Petrosal (2008) (SOLOMON, 2008). Sin hablar del episodio ocurrido en 2003, cuando el Banco Nacional de Desenvolvimento Econômico e Social - BNDES volvió a comprar 8,5\% de las acciones de Valepar, detentadora del control accionario de la Vale do Rio Doce, que había sido privatizada en 1997, 
con la justificación de que, garantizando más un lugar en el Consejo Administrativo de la controladora, el gobierno podría impedir el control de la compañía por extranjeros en el futuro (FRANÇA, 2003).

Se nota, en ese caso, la prevención en contra del extranjero. No es exagerado decir que las leyes brasileñas son poco receptivas a las inversiones extranjeras - uno de los principales blancos de las golden shares - pese a que la Enmienda Constitucional $n^{\circ} 6$ haya abolido, en 1995, la distinción entre empresas brasileñas de capital nacional y extranjero. De eso es prueba la propia Ley 9.491/1997, el PND, que por su art. 12 establece la apertura al capital extranjero con una importante y discrecional salvedad: "a alienação de ações a pessoas físicas ou jurídicas estrangeiras poderá atingir cem por cento do capital votante, salvo disposição legal ou manifestação expressa do Poder Executivo, que determine percentual inferior."

Otra razón para conferir importancia al tema es el hecho de que, con el establecimiento, en Europa, de una jurisprudencia limitadora de estas restricciones, las empresas europeas, que están viendo sus propios gobiernos abolir las golden shares en sus países - aunque sólo a costa de presión de las instituciones de la Unión Europea -, tienden a ser menos tolerantes con la posibilidad de aceptar, sin más, la previsión de estas restricciones en terceros países, en los que son llamados a invertir. No ven con buenos ojos un tal intervencionismo, la previsión de un mecanismo de interferencia del gobierno en el futuro de las empresas privatizadas.

Aunque sean pocas las empresas en las que el gobierno brasileño detenta actualmente acciones de oro, han sido muchas las ocasiones en que, últimamente, se ha hablado de ellas como la panacea del momento. ¿Qué seguridad jurídica puede encontrar un inversor europeo en un país cuya legislación amenaza con inmiscuirse en las más mínimas decisiones de gestión y, hasta, retomar las riendas del negocio en cualquier momento, una vez que tiene poder de veto - o poderes aún más amplios, como en el caso de Brasil - en las más diversas materias?

No deja de ser verdad que gobiernos europeos como el italiano, el alemán o el francés, son muy reacios a la compra de sus empresas por otras extranjeras y que, cuando ven el mínimo riesgo de que sus empresas 
nacionales sean compradas por capital extranjero, se mueven en el sentido de usar todas las armas proteccionistas a su alcance para impedir la venta - sin embargo, los perjudicados siempre tienen el recurso de quejarse a las instituciones de la Unión Europea por el atentado a principios de los Tratados, garantía con la que no cuentan las empresas extranjeras que se establezcan en un tercero país, aunque sí, obviamente, siempre puedan acceder a los tribunales judiciales.

En ello Brasil sabe muy bien imitar los europeos, como ha sucedido recientemente en el caso de las teles, cuando el gobierno habló en crear un gigante nacional de telecomunicaciones a partir de la fusión entre Oi (antigua Telemar) y Brasil Telecom, estableciendo una golden share, lo que dejó los empresarios con los pelos de punta ante el riesgo de reestatización con la influencia política en un sector que desde 1998 se encuentra en manos de la iniciativa privada.

Sería un cambio en las reglas del juego para unos inversores internacionales que, durante la privatización de las empresas de telecomunicaciones, en ningún momento fueron impedidos de ingresar en el mercado brasileño por su condición de extranjeros y tampoco fue prevista cualquier ação de classe especial entonces en el sector.

Pero ¿Cuál es el problema con esas acciones de oro?

Aparte de los casos puntuales y muy restrictos en que, sí, está justificada la utilización de una golden share, su amplia previsión en los estatutos de empresas privatizadas o la mera alusión a su institución en sectores que hasta ahora no habían sido previstas, provocan no pocas veces una inseguridad jurídica que en nada ayuda los gobiernos a contar con la colaboración de un sector privado que necesita, antes de todo, conocer los riesgos efectivos en que incurre al aceptar invertir en un determinado negocio.

De otra parte, las golden shares provocan una pérdida de valor para la empresa privatizada y sus accionistas, por el hecho de que estorban, y hasta imposibilitan, la compra de la sociedad por terceros con mejores ideas y proyectos empresariales. 
La previsión de tales restricciones trae consigo la concepción de que el mercado y la competencia no son de fiar. Los gobiernos privatizan, pero lo hacen de manera parcial con las acciones de oro, por que no acaban de dar crédito al mercado y a la competencia.

Procediendo a una privatización parcial, en la que se quebranta por lo menos dos de los derechos de propiedad (el ius utendi y el ius disponendi) a través de tales limitaciones - las acciones de oro -, en lo que realmente creen los gobiernos es que el interés público es monopolio del Estado y sólo él puede asegurarlo (ARIÑO ORTÍZ; GUIRADO, 2006, p. 20).

Una idea que no se sostiene, haya vista lo que ya dijo Friedrich A. von Hayek, refiriéndose al concepto de interés general:

El bienestar común o público ha sido concepto que siempre se ha resistido a una definición precisa [...] En la Gran Sociedad, ámbito en el cual los individuos gozan de la libertad de hacer uso de sus particulares conocimientos aplicados al logro de su individuales metas, el bienestar común que el gobierno debe propiciar no puede consistir en la satisfacción de un conjunto de apetencias particulares, por la sencilla razón de que ni éstas, ni cuantas circunstancias las determinan, pueden ser conocidas por el gobierno, ni por cualquier otro ente. [...] El más importante bien colectivo a proporcionar por el gobierno no consiste en la satisfacción directa de las necesidades personales, sino en la creación de un conjunto de condiciones en base a las cuales los individuos pueden ocuparse de la satisfacción de las mismas. (HAYEK, 1979, p. 5-7).

En otras palabras, es el libre mercado - con la necesaria y suficiente regulación -, a través de sus individuos y empresas en competencia, quien mejor puede servir al interés público.

\section{Conclusiones}

Mientras formaban parte del patrimonio del Estado, el interés general estratégico al que estaba afectado el objeto y las actividades de 
determinadas empresas se encontraba suficientemente protegido. Una vez enajenadas las participaciones accionariales del Estado a terceros, ya no había garantía de protección de aquel interés, lo que, entendían los Estados, les legitimaba, mediante sus legisladores, a reservarse cláusulas especiales atribuyéndose ciertos derechos de intervención en la actividad de la empresa privatizada, que quedaba así limitada por el poder de veto estatal.

Brasil - y otros países Latinoamericanos, herederos de la tradición jurídica europea continental -, no dejó pasar la oportunidad de, en la estela de las legislaciones europeas, hacer previsión en su ordenamiento jurídico de similares restricciones.

Pese a que las ações de classe especial brasileñas hayan pasado desapercibidas en el debate jurídico del país, las golden shares - para utilizar aquí la denominación original inglesa - tienen gran protagonismo en el ámbito de la Unión Europea. Un gran número de artículos jurídicos sobre el tema ha sido publicado desde hace más de una docena de años en los Estados miembros.

La utilización de las acciones de oro viene siendo combatida por las instituciones comunitarias en cuanto restringen injustificadamente las libertades de circulación de capitales y de establecimiento en el seno del mercado único, haciendo que empresas europeas se vuelvan menos tolerantes con este tipo de intervención gubernamental, incluso en terceros países.

Si algún día la amplia utilización de las golden shares tuvo alguna justificación - el paso de una significativa cantidad de empresas públicas para manos privadas sin que se tuviera la certeza que la masiva privatización atendería al interés general en la práctica - en el contexto actual - superada la novedad del proceso y surgida una jurisprudencia comunitaria que recorta su utilización dentro de unos límites pautados por las exigencias del interés general y por los principios de la proporcionalidad - tales restricciones sólo se justifican en casos muy puntuales. 
La previsión de golden shares con amplios poderes en las empresas privatizadas o la mera alusión a la institución de estos mecanismos en un contexto de reorganización del mercado, por ser un recurso fácilmente utilizable por gobiernos tendientes a una política estatalizante, tiene la capacidad de arañar la imagen de Brasil en el exterior y causar un temor generalizado en los inversores extranjeros.

\section{Referencias}

ÁLVAREZ, Enrique; CALLEJA, Angel. Privatizaciones y el sistema de la acción especial ("golden share”). Economistas, Madrid, n. 63, p. 4453, ene./mar. 1995.

AMEAÇA nacionalista à Vale. Folha de São Paulo, São Paulo, 31 jan. 2008.

ARIÑO ORTÍZ, Gaspar. Acciones de oro y otros artefactos (I). Diario Expansión, Madrid, 23 may. 2000.

ARIÑO ORTÍZ, Gaspar; GUIRADO, Rosa. El desafío europeo y los nacionalismos rampantes. In: ARIÑO Y ASOCIADOS ABOGADOS, Energía en España y desafío europeo: seguridad, concentración empresarial, competencia, regulación. Granada: Comares, 2006. Cap. 1, p. 1-40.

CANO SOLER, Diego. Políticas de privatización: aproximación teórica: experiencias prácticas y propuesta para España. Madrid: Consejo Económico y Social de España, 1998.

CASTELAR PINHEIRO, Armando; FUKASAKU, Kiichiro. A privatização no Brasil: o caso dos serviços de utilidade pública. Rio de Janeiro: BNDES, 2000.

CHASPORT, Danielle; RAMADIER, Sylvie. Privatisation d'Elf Aquitaine: l'Etat proposera l'échange des certificates pétroliers. Les Echos, Paris, n. 16529, p. 26, 1 dec.1993. 
CHRISPIN MARIN, Denise. Lula envolve Embraer em plano para argentina AMC. Revista Exame. Disponible en: < http://portalexame.abril. com.br/ae/economia/m0167445.html\#> Acceso el: 22 set. 2008.

FRANÇA, Ronaldo. A última do doctor Lessa. Revista Veja. Edição núm. 1830. São Paulo, 26 nov. 2003.

GONÇALVES FERREIRA FILHO, Manoel. Curso de direito constitucional. 31. ed. São Paulo: Saraiva, 2005.

GARCÍA-MORATO, Lucía López de Castro; ARIÑO ORTÍZ, Gaspar. Derecho de la competencia en sectores regulados: fusiones y adquisiciones, control de empresas y poder político. Granada: Comares, 2001.

GIPPINI FOURNIER, Eric; RODRÍGUEZ MIGUEZ, José Antonio. Golden shares en la Comunidad Europea: ¿fin de la edad dorada? Gaceta jurídica de la Unión Europea y de la competencia, Madrid, n. 220, p. 3862, jul./ago. 2002.

HAYEK, Friedrich August von. Derecho, legislación y libertad, una nueva formulación de los principios liberales de la justicia y de la economía política, v. II. El espejismo de la justicia social. Traducción de Luis Reig Albiol. Madrid: Unión Editorial, 1979.

HERNÁNDEZ LÓPEZ, Manuel. Las acciones de oro y la Comisión Europea. Información Comercial Española, ICE: Revista de economía, Madrid, n. 831 (Ejemplar dedicado a: Las políticas comunitarias: una visión interna), p. 157-164, jul./ago. 2006.

HINOJOSA MARTÍNEZ, Luis Miguel. La acción de oro en Derecho comunitario: activismo judicial versus intervencionismo estatal. Gaceta jurídica de la Unión Europea y de la competencia, Madrid, n. 228, p. 1131, nov./die. 2003.

JACQUIN, Jean-Baptiste. Privatisation d'Elf Aquitaine: L'Etat se donne une action spécifique. Les Echos, Paris, n. 16538, p. 7, 14 dec. 1993.

KUZNETSOV, Ivan. The legality of golden shares under EC Law.

Disponible en: <www.hanselawreview.org> Acceso el: 15 ago. 2008. 
LA “ACCIÓN DE ORO”, un instrumento de control estatal sobre las compañías privatizadas. Diario Cinco Días, Madrid, 06 feb. 2006.

LAFFITTE, Michel. Las privatizaciones en Francia. Boletín Económico ICE: Información Comercial Española, Madrid, n. 2405, p. 705-711, 1420 mar. 1994.

MARQUES, Gerusa. Costa vê fusão das teles com simpatia. O Estado de S.Paulo, São Paulo, 10 abr. 2007.

MUÑOZ MACHADO, Santiago. Tratado de derecho administrativo y derecho público general. T. I. Madrid: Civitas, 2004.

ORTEGA ALMÓN, María Ángeles. La empresa pública y el proceso privatizador en España. Granada: Instituto de Desarrollo Regional, 2002.

PRADO, Paulo. Retrato do Brasil: ensaio sobre a tristeza brasileira. São Paulo: Schwarcz., 2001.

REAL ACADEMIA ESPAÑOLA. Diccionario de la lengua española. 22. ed. Madrid: Espasa Calpe, 2001.

RIDRUEJO, Pablo Siegrist; MERCHÁN, Jesús Lavalle; GONZÁLEZ, Emilia Gargallo. La acción de oro o el problema de las privatizaciones en un mercado único. Serie de documentos de trabajo de política de la competencia del Instituto de Estudios Europeos, Madrid, Centro de Política de la Competencia del Instituto de Estudios Europeos, feb. 2003.

RITTNER, Daniel. Governo quer ter “golden share” na indústria bélica. Valor Econômico, São Paulo, 10 abr. 2008.

ROLDÁN MARTÍN, Áurea. Los nuevos contornos del servicio público. In: ORTEGA MARTÍN, Eduardo. (Dir.) Cuadernos de derecho judicial (Ejemplar dedicado a: Derecho administrativo-económico). Madrid: Consejo General del Poder Judicial, 2000. Cap. 1, p. 15-56.

RUIZ DE HUIDOBRO, Adolfo Domínguez. Observaciones a la Ley 5/1995 de 23 de marzo, de régimen jurídico de enajenación de participaciones públicas en determinadas empresas. Revista de derecho bancario y bursátil, Valladolid, n. 58, p. 449-476, abr./jun. 1995. 
SÁNCHEZ, Amelia. Las acciones de oro condenadas a desaparecer: una sentencia del Tribunal de Justicia de la U.E. obliga a España a abolir el régimen que las autoriza. Bolsa de Madrid, Madrid, n. 120, p. 32-35, may 2003.

SANTONASTASO, Felice. La “saga” della "golden share” tra libertà di movimento di capitali e libertà di stabilimento. Giurisprudenza commerciale, Milano, v. 34, n. 3, p. 302-348, 2007.

SOLOMON, Alexandru. Petro-sal, Petoro e outras fantasias. O debate, Belo Horizonte, 27 ago. 2008.

TAPIA HERMIDA, Antonio. La acción de oro ("golden share”). Revista de derecho bancario y bursátil, Valladolid, n. 110, p. 199-255, abr./jun. 2008.

UNITED STATES. U. S. Department of Energy: Energy Information Administration. Privatization and the globalization of energy markets, oct. 1996. Disponible en: <www.eia.doe.gov/emeu/pgem> Acceso el: 15 ago. 2008.

URÍA FERNÁNDEZ, Francisco. El régimen de autorización administrativa previa de la Ley 5/1995, de 23 de marzo, como mecanismo jurídico complementario a la política de defensa de la competencia. Anuario de la competencia, Madrid, n. 1, p. 171-194, 2000. VERGARA ESTÉVEZ, Jorge. El mito de las privatizaciones en Chile. Polis Revista Académica de la Universidad Bolivariana, Santiago de Chile, v. 3, n. 12, 2005.

Enviado em: 02/2010 Aprovado em: 05/2010 